\title{
Arbovirosis y operación ATALANTA: riesgo para viajeros y medidas de prevención y control
}

\author{
Plaza Torres JF. ${ }^{1}$, Navarro Suay R. ${ }^{2}$
}

Sanid. mil. 2014; 70 (2): 103-113; ISSN: 1887-8571

\begin{abstract}
RESUMEN
El término arbovirosis se utiliza para definir a un grupo de enfermedades producidas por virus, que tiene en común la utilización de artrópodos como vectores para su transmisión. Se han reconocido más de 500 arbovirus pertenecientes en su mayoría a 5 familias: Flaviviridae, Togaviridae, Bunyaviridae, Reoviridae y Rhabdoviridae. Pese a su naturaleza mayoritariamente zoonótica, al menos un $25 \%$ de ellas afectan al hombre, siendo responsables de enfermedades como la fiebre amarilla, dengue o la fiebre de Chikungunya. Desde enero de 2009 un contingente militar se encuentra desplegado en el Golfo de Adén y en el Océano Indico integrado en la operación EU NAVFOR-ATALANTA de lucha contra la piratería y protección del tráfico mercante del Programa mundial de alimentos para Somalia. Las enfermedades transmitidas por vectores, en especial la malaria y diversas arbovirosis (dengue, Chikungunya, fiebre del Valle del Rift, fiebre del Nilo occidental) se consideran un importante problema de salud pública en el area de operaciones (sobre todo en zonas rurales y/o costeras). Los vectores de estas enfermedades se encuentran ampliamente distribuidos por toda esta región, con tasas de infestación muy altas y que se incrementa de año en año. Por todo ello nos planteamos este trabajo cuyos objetivos son: conocer las características epidemiológicas de las principales arbovirosis que pueden afectar a las tropas españolas desplegadas en la operación Atalanta: fiebre del Valle del Rift, fiebre de O'nyong Nyong, fiebre del Nilo occidental, fiebre hemorrágica del Congo, fiebre amarilla, enfermedad de Sindbis, fiebre de Chikungunya y Dengue. Así mismo se pretende analizar las principales medidas para la prevención de estas enfermedades realizadas por el contingente español allí desplegado: educación sanitaria, control ambiental, protección frente a mosquitos.
\end{abstract}

PALABRAS CLAVE: Operación Atalanta, Arbovirus, Medidas preventivas de enfermedades transmitidas por vectores.

Arbovirosis and Operation Atalanta: risk for travelers and prevention and control measures.

SUMMARY: The term arbovirosis is used to define a group of diseases produced by virus transmitted by arthropod vectors. More than 500 arbovirus have been recognized most of them belonging to 5 families: Flaviviridae, Togaviridae, Bunyaviridae, Reoviridae $y$ Rhabdoviridae. Although they are mainly zoonotic, at least $25 \%$ of them affect humans, being responsible for diseases like yellow fever, dengue or Chikungunya fever. Since January 2009 a military contingent is deployed in the Gulf of Aden and the Indian Ocean integrated in the operation EU NAVFOR-ATALANTA against piracy and protecting the merchant traffic of the World Food Programme Somalia. Vector borne diseases, especially malaria and different arbovirosis (dengue, Chikungunya, Rift Valley fever, West Nile fever) are considered an important public health issue in the Area of Operations (mainly in rural or coastal areas). The vectors of these diseases are widely distributed throughout the region with high infestation rates and increasing every year. This is the reason for this paper with the objectives of: to determine the epidemiological characteristics of the main arbovirosis that might affect the Spanish forces deployed in Operation Atalanta: Rift Valley fever, O'nyong'nyong fever, West Nile fever, Congo hemorrhagic fever, yellow fever, Sindbis virus disease, Chikungunya fever and dengue. It also aims to evaluate the main preventive measures against these diseases used by the deployed Spanish contingent: health education, environmental control and protection against mosquitoes.

KEY WORDS: Operation Atalanta, Arbovirus, Preventive measures against vector borne diseases.

\section{INTRODUCCIÓN}

Desde los últimos 30 años del siglo XX hemos asistido a la aparición de nuevas enfermedades virales y a un aumento en el número de epidemias causadas por virus del tipo arbovirus.

Diversos factores han influido en estos fenómenos:

- Las variaciones ecológicas, especialmente en las zonas tropicales, han tenido como consecuencia la exposición

${ }^{1}$ Cte. Médico. Escuela de Suboficiales de la Armada. San Fernando Naval. Cádiz. España.

${ }^{2}$ Cte. Médico. Hospital Central de la Defensa Gómez Ulla. Servicio de Anestesiología y Reanimación. Madrid. España.

Dirección para correspondencia: Cte. Plaza Torres. Escuela de Suboficiales de la Armada, San Fernando Naval (11100), Cádiz. jplator@fn.mde.es

Recibido: 6 de mayo de 2013

Aceptado: 12 de junio de 2013 del hombre a muchas de estas infecciones con los consiguientes problemas de Salud Pública.

- La expansión de los vectores de estas enfermedades se ha traducido en la aparición de epidemias en zonas no endémicas. Así, la colonización de determinadas regiones de nuestro país por vectores de infecciones tropicales como Aedes albopictus ${ }^{1}$ podría llegar a ocasionar brotes autóctonos. Esta posibilidad se convirtió en un hecho durante el verano del 2007 en Italia: 207 personas se vieron afectadas por un brote local de virus CHIK transmitido por A. albopictus a partir de un viajero virémico procedente de la India ${ }^{2}$. En otras ocasiones, los patógenos se introducen en nuevas áreas geográficas y aprovechan la existencia de vectores ya presentes en la zona, así se produjó la epidemia de VWN en EEUU durante $1999^{3,4}$. 
- El aumento de viajeros internacionales y los movimientos migratorios han favorecido la globalización de las enfermedades infecciosas ${ }^{5}$. Los CDC definen a los viajeros, inmigrantes y refugiados como una de las dianas en la estrategia de prevención de la emergencia de las enfermedades infecciosas. Esta situación no es nueva para la humanidad. La diseminación de la peste en Europa durante la edad media, o la introducción de nuevos patógenos en territorios vírgenes, como el sarampión o la viruela con la colonización de América, son ejemplos de la asociación entre enfermedades transmisibles y los movimientos demográficos. Durante el año 2008, se produjeron más de 900 millones de desplazamientos más allá de las fronteras de origen de esos viajeros (5). En España cada año viajan de 12 a 13 millones de personas al extranjero, de las que unas $950.000(9 \%)$ lo hacen hacia zonas tropicales de ellos 280.000 son a África (30.000 a África Subsahariana). La Internacional Society of Travel Medicine constata que aproximadamente el $10 \%$ de los viajeros acudirán al médico al regreso del viaje, lo que aplicado a nuestro país supone unas 100.000 consultas al año ${ }^{6,7}$. Las infecciones, la mayoría de ellas prevenibles, son la primera causa de morbilidad al regreso de un viaje al trópico ${ }^{8}$. El grupo de los viajeros tiene su propia idiosincrasia. El hecho de que personas inmunocompetentes se expongan a ciertas infecciones, con las que nunca antes han tenido contacto, provoca cambios en las características de la enfermedad: la frecuencia de adquisición, el modo de presentación y la gravedad de la misma son distintas respecto a las que se producen en personas que llevan tiempo viviendo en una zona endémica.

En general, el riesgo de adquisición de una enfermedad infecciosa y de una arbovirosis, en particular, depende de los siguientes factores: 1) Zona Geográfica (destino geográfico, ruta específica seguida, duración, tipo de viaje, estación del año), 2) Tipo de Viajero según estas definiciones: Viajeros de alto riego como cooperantes, misioneros, guías o viajeros de aventura), que visitan áreas con mayor prevalencia de enfermedades infecciosas y mantienen un contacto estrecho con nativos y Viajeros de bajo riego que viajan por un trabajo que no les expone a gran riego (diplomáticos, negocios, azafatas) o en viajes organizados a hoteles acondicionados y con poco contacto con personas locales, y 3) Realización o no de Medidas Preventivas.

Los militares desplazados en misiones internacionales constituyen una población con características demográficas, de destino y de necesidades diferentes al grupo de viajeros civiles. Las características que los distinguen como un colectivo diferente son la siguientes ${ }^{9,10}$ :

- Se trata de personal seleccionado que por tanto no debe padecer de problemas de salud de importancia.

- En la Fase de Planeamiento de cada misión se tiene en cuenta las características sanitarias de la ZO y en base a estas se indican las medidas de profilaxis necesarias.

- Durante la Fase de Concentración se realiza un asesoramiento en materia de Salud Internacional, adquiriendo cada vez mayor relieve los aspectos relacionados con la Educación para la Salud del contingente. El asesoramiento se suele hacer a nivel colectivo y no individual.

- La quimioprofilaxis antipalúdica suele utilizarse, cuanto está indicada, y tal como apuntan distintos estudios americanos durante tiempos más prolongado que en la vida civil.

- Las actividades se limitan a aspectos relacionados con cada misión. Sin la exposición que conllevan otras actividades relacionadas con el turismo (senderismo o visitas a parques naturales).

Desde el 28 de enero de 2009 un contingente militar español compuesto por 230-400 efectivos se encuentra desplegado en el Golfo de Adén y el Océano Indico en rotaciones de unos 5 meses en el transcurso de la Operación auspiciada por la UE (EU NAVFOR-ATALANTA) de lucha contra la piratería y protección del tráfico mercante del Programa Mundial de Alimentos para Somalia.

Las enfermedades transmitidas por vectores y, en especial, la malaria y diversas arbovirosis son problema importante de Salud Pública en este Área de Operaciones (AO). En algunas regiones, presentan un patrón de transmisión constante durante el año; pero, en general, es estacional y coincide con los meses posteriores a la temporada de lluvias. Los vectores de estas enfermedades se encuentran ampliamente distribuidos por toda el AO con tasas de infestación localmente muy altas y que se elevan cada año, especialmente en zonas urbanas y costeras. La distribución de casos por países, conocida mediante datos oficiales, puede estar subestimada por la carencia de servicios sanitarios y sistemas de registro fiables.

Algunas de estas enfermedades, como el DEN y el CHIK, son poco conocidas en nuestro país. Sin embargo, debemos tener presente la posible emergencia en España de algunas de estas arbovirosis cuya incidencia mundial ha aumentado en los últimos años. La reciente introducción, establecimiento y expansión del Aedes albopictus, abre una preocupante vía para la aparición de brotes de arbovirosis como el DEN o el CHIK importadas a nuestro país por personas inmigrantes, turistas o cooperantes.

Por todo ello, resulta de interesante conocer estas arbovirosis endémicas de esta Zona de Operaciones (ZO), sus características epidemiológicas y las principales medidas para la prevención de estas enfermedades realizadas por la fuerza española.

Para la realización de este informe hemos recopilado los datos epidemiológicos suministrados por los siguientes Hospitales en los años 2009 y 2011: Hospital Militar Francés Bouffard de Djibouti, Hospital Agha Kan de Mombasa (Kenia), Hospital Aga Kan de Der es Salem (Tanzania), Hospital de Port victoria (I. Seychelles) y Clínica Sultán Qaboos de Salalah (Omán), así como los datos suministrados por el Cuartel General Operacional de la Misión en Norwood para conocer las principales enfermedades infectocontagiosas y, en especial, las arbovirosis que afectan estos países. La recolección de datos se realizó por entrevista directa con las autoridades sanitarias de los centros anteriormente mencionados de Djibouti, Mombasa, Tanzania, Omán y Seychelles y por solicitud indirecta a través del enlace medico en Norwood. 


\section{ÁREAS GEOGRÁFICAS}

De forma general desde el punto de vista sanitario podemos diferenciar dos grandes áreas en la zona geográfica que nos ocupa:

\section{Djibouti, Kenia Somalia y Tanzania}

Son países pobres cuyas características económicas, sociales e infraestructuras, son muy similares. Sus economías, fundamentalmente agrarias, experimentan problemas de sequía y desertización crecientes y existen fuertes movimientos migratorios del campo a la ciudad.

Desde el punto de vista higiénico-sanitario, la situación general es precaria y ha empeorado en los dos últimos decenios. Crece el hacinamiento en las ciudades, el alcantarillado prácticamente no existe, la mayoría de los barrios carecen de servicios higiénicos y agua corriente y las basuras se suelen acumular en las calles sin ser recogidas, lo que facilita la proliferación de artrópodos y roedores (figuras 1 y 2). En los últimos años se ha asistido a un crecimiento demográfico y en especial a un importante flujo migratorio del campo a la ciudad, relacionado con las sequías, el agotamiento de los recursos naturales y la desertización. El crecimiento de las ciudades ha creado anillos periféricos que carecen de las infraestructuras mínimas y facilitan la propagación de las enfermedades infectocontagiosas. Se estima que más del $60 \%$ de la población no tiene acceso real a los servicios básicos de salud, que más de la mitad de la población no puede adquirir medicamentos y que las campañas de vacunación no alcanzan el porcentaje mínimo necesario de la población.

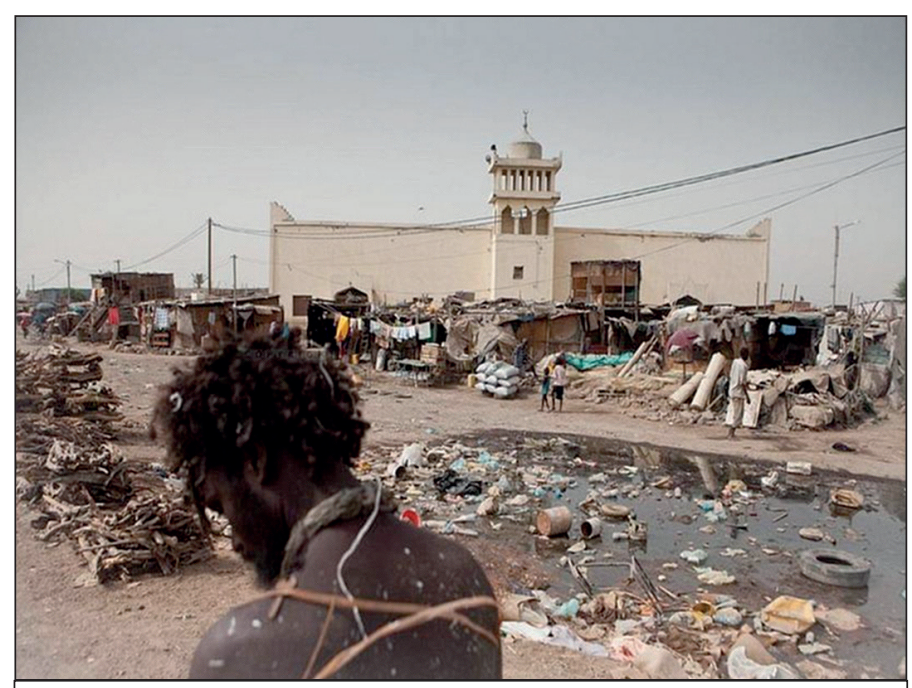

Figura 1. Imagen de las condiciones medioambientales de la zona de operaciones.

En el caso concreto de Somalia se trata de un país con una situación de conflicto crónico que lo ha convertido en un "estado fallido". Es un país muy pobre, con infraestructuras muy deficientes, con servicios sanitarios deficientes e indicadores de un muy pobre estado de salud de la población, donde todo lo comentado en los párrafos anteriores se incrementa de forma sustancial.

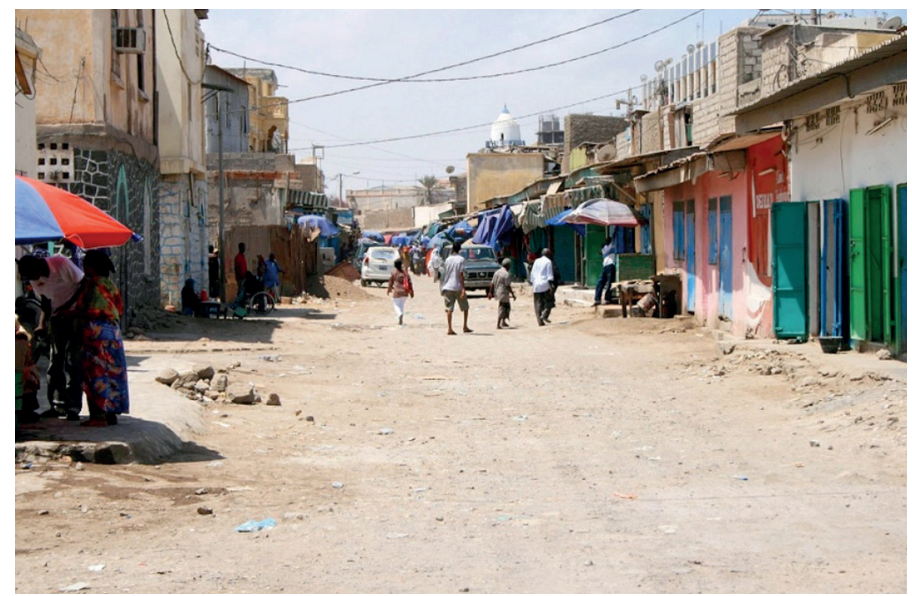

Figura 2. Imagen de un poblado local de la zona de operaciones.

\section{Oman y Seychelles}

Se trata de dos países donde en los últimos 10-15 años se han producido una serie de cambios económicos, sociales y de infraestructuras que han hecho que hoy en día se consideran que tienen un Nivel de Riesgo Intermedio para la adquisición de Enfermedades trasmisibles.

\section{CARACTERÍSTICAS EPIDEMIOLÓGICAS DE LAS PRINCIPALES ARBOVIROSIS DETECTADAS EN ESTA ZO}

En el área geográfica que nos ocupa destacan las siguientes:

\section{Fiebre del Valle Del Rift (VFVR)}

Es una enfermedad causada por un Virus-RNA, género Phlebovirus de la familia de los Bunyaviridae: Virus de la fiebre del Valle del Rift y cuyo reservorio son las ovejas y los rumiantes. Los vectores son mosquitos pertenecientes a los géneros Aedes (A. incintoshi), Anopheles, Culex (C. pipiens), Eretmapodites y Mansonia. Las fuentes de virus para el contagio humano son secreciones nasales, sangre, secreciones vaginales (después del aborto en animales), mosquitos y carne infectada. Posiblemente también aerosoles y leche cruda infectada.

Distribución geográfica: La enfermedad fue descrita por primera vez en Kenia en 1931 en uno de los lagos del Valle del Rift. Endémica o potencialmente endémica en 35 países. Ha sido identificada exclusivamente en los países africanos. El único foco epizoótico fuera de África Subsahariana, fue notificado en Egipto en 197778 y en 1993, así como en Mauritania en 1987. Se han notificado infecciones de laboratorio en otras partes del mundo. Las últimas epidemias se han producido entre los años 2000-01 en África, en Yemen y Arabia Saudita, en el 2003 en Egipto y en los años 20062007 en Kenia, con casos adicionales en Somalia y Tanzania.

Diversas Alertas Sanitarias de esta enfermedades han sido notificadas en $\mathrm{ZO}$ :

- Kenia: El 12 de Marzo de 2007 se habían notificado 684 casos sospechosos de VFVR, en las provincias Nororien- 
tal y Costera de Kenia. La zona más afectada es el distrito de Garissa, donde se han registrado 333 casos, 183 casos en la Provincia del valle del Rift, 141 en la Provincia de Costera, 14 en la Provincia Central y 13 en la Provincia Oriental.(WHO, EPR Mayo 2007). Esta se propagó por el sur de Somalia y Tanzania.

- Tanzania: En marzo de 2007, en la zona norte del país aparecieron brotes desde el 13 de Enero hasta el 3 de Mayo del 2007, se han notificado un total de 264 casos en Arusha, Dar es Salaam, Dodoma, Iringa, Manyara, Morogoro, Mwanza, Pwani y Tanga (OMS, Mayo 2007).

\section{Fiebre de $\mathbf{O}^{\prime}$ Nyong Nyong}

Enfermedad causada por un Virus - RNA, Alfavirus: Virus O'nyong nyong cuyo reservorio es desconocido. El vector es el mosquito (Anopheles funestus y An. gambiae).

Distribución geográfica: Solo se ha notificado en África, principalmente en la región Oriental, siendo la última epidemia que se ha producido en 1996-1997, empezando en Junio de 1996 en el suroeste de Uganda, desde allí se extendió al norte de Tanzania (distrito de Bukuba) y en el año 1997 se extiende a Uganda. Se han notificado casos en República Centroafricana, República Democrática del Congo, Ghana, Costa de Marfil, Kenia, Liberia, Malawi, Mozambique, Nigeria, Senegal, Sierra Leona, Sudán, Tanzania, Uganda.

En Kenia se notificó un brote epidémico en el 2004 con 150 casos confirmados en Mombasa y Malindi y en Tanzania en la década de noventa se describieron caso propagados desde Uganda.

\section{Fiebre del Nilo Occidental (West Nile) (VWN)}

Enfermedad causada por un Virus - RNA, Flavivirus: Virus del Nilo Occidental. El reservorio son principalmente las aves, aunque se ha demostrado que el virus también puede infectar a otros animales. El virus se transmite mediante mosquitos, sobre todo, el Culex sp., género que pica de noche. En África y el Medio Oriente, los principales vectores son Culex univittatus y C. pipiens; en América del Norte C. pipiens ; el Cu. Modestus en Francia; Otros vectores son: $\mathrm{Cu}$. Vishnui, el $\mathrm{Cu}$. neavei, Coquillettidia, Aedes y Anopheles spp. Los mosquitos se infectan cuando se alimentan al picar pájaros infectados y mantienen el virus en la sangre durante algunos días. El virus se encuentra en las glándulas salivales del mosquito, por lo que al picar, inyecta el virus en el humano o en el animal, en éstos, el virus puede multiplicarse y posiblemente causar la enfermedad.

Distribución geográfica: Este arbovirus fue descubierto originalmente en 1937 en el "West Nile District" de Uganda. Endémica o potencialmente endémica en 78 países. Se producen casos principalmente en África, América del Norte, Asia (subcontinente indio y ex unión soviética), Europa y Oriente Medio. En Kenia y Tanzania se detectan casos en todo el país, siendo el riesgo más elevado en las zonas del Lago Victoria y las zonas costeras; en Somalia existe riesgo en todo el país pero es más elevado en el sur, se observaron casos de VWN entre las fuerzas americanas desplegadas en Mogadiscio durante 1993. En el año
1996 hubo una epidemia en Rumanía con 835 casos, siendo la primera en Europa. Se han notificado brotes en Canadá, Egipto, EEUU, Francia, India, Israel, República Checa y Rumanía.

\section{Fiebre (Hemorragica de) Crimea-Congo (FHCC)}

Enfermedad causada por un Arenavirus: Virus Crimea-Congo cuyo reservorio son liebres y diversos tipos de pájaros. Se infecta por la picadura de una garrapata del género Hyalomma marginatum o $H$. anatolicum al aplastarla y por manipular tejidos o sangre de un animal infectado. Son frecuentes las infecciones nosocomiales por exposición a sangre y tejidos de pacientes infectados. La infección confiere inmunidad.

Distribución geográfica: Se describió en Crimea en 1944 y en el Congo (Kinshasa) en 1956. Se presenta principalmente en gran parte de África (subsahariana y sur), Oriente Medio (Omán, Emiratos árabes Unidos, Arabia Saudí, Kuwait), la antigua Unión Soviética y China. Se encuentra en las estepas de Crimea occidental y en Rostov y Astracán en la Federación Rusa, así como en Afganistán, Albania, Bosnia y Herzegovina, Bulgaria, China Occidental, Irak, Irán, Kazajstán, Pakistán, Sudáfrica, Turquía, Uzbekistán, Península arábiga y África Subsahariana. Las últimas epidemias se han producido en los años 2005 en Kazajstán, Federación rusa y Pakistán y en el 2006 en Pakistán y la Federación rusa.

\section{Fiebre Amarilla}

Enfermedad causada por un virus - RNA, Flavivirus: Virus de la Fiebre Amarilla. El reservorio son los humanos y los mosquitos; monos y marsupiales en las áreas forestales. El vector son los mosquitos, en las zonas urbanas el Ae aegypti y en las zonas selváticas: Ae africanus (África), Haemagogus (América: Haemagogus janthinomys, $H$. spegazzinii, H. leucocelaenus, $H$. equinus, H. mesodentatus, $H$. lucifer, $H$. iridicolor, H. capricornii, H. albomaculatus), Sabethes (América: Sabethes chloropterus). Entre los rebrotes de FA en monos, el virus sobrevive gracias a la transmisión transovárica en mosquitos.

Hay tres modelos de transmisión de la enfermedad: Selvático, Intermedio y Urbano. En África concurren los tres, mientras que en Sudamérica, solo aparece el selvático y el urbano.

Distribución geográfica: Endémica o potencialmente endémica en 45 países. Las formas endémicas y epidémicas de FA se producen en el África Tropical, entre los $15^{\circ}$ latitud norte y $10^{\circ}$ latitud sur, es decir, en el límite meridional del Sáhara hasta Angola, República Democrática del Congo y Tanzania y de la costa oriental a la occidental en longitud geográfica. En América del sur, entre los $10^{\circ}$ latitud norte y $20^{\circ}$ latitud sur, comprendiendo el bajo Amazonas y el sur de América central. Actualmente en África, 33 países, con una población de 508 millones de personas, están en riesgo. En América la FA es endémica en 9 países sudamericanos y se consideran zonas de alto riesgo Bolivia, Brasil, Colombia, Ecuador y Perú. Más del 70\% de los casos de América se notifican en Perú y Bolivia.

Las últimas epidemias en África se han producido en el año 2001, en Costa de Marfil, año 2003 en Burkina Faso y en Sudán, 


\section{Arbovirosis y operación ATALANTA: riesgo para viajeros y medidas de prevención y control}

2004 y 2005 en Burkina Faso. En África se han notificado 2.663 casos con 269 fallecidos en el año 2005. En el año 2003 se estimó que sólo el 22\% de la población estaba vacunada. En América: Argentina, Bolivia, Brasil, Colombia, Ecuador, Guyana, Panamá, Paraguay, Perú, Trinidad y Tobago, Venezuela produciéndose 117 casos en el año 2005 con 52 fallecidos. En el año 2003 se estimó que la cobertura vacunal alcanzó al $64 \%$ de la población.

Es interesante comentar que en Kenia la enfermedad es endémica en los distritos de Keiyo, Marakwet, Baringo y Koibatek, otras áreas de riesgo son: Gishu, Kericho, Nakuru, Nandi y Uasin; en 1995 se produjo una epidemia con 53 casos. No se han producido casos desde entonces. En Tanzania existen focos diseminados por todo el país, notificándose casos en la décadas de los 90. Con respecto a Somalia en el año 1993 fueron tratados en el Hospital Militar Marroquí desplegado en Mogadiscio refugiados afectados de FA.

Riesgo para los viajeros: El riesgo es normalmente bajo, pero la inmunización está indicada a viajeros mayores de 9 meses, que se dirijan a áreas endémicas o epidémicas de FA. El Certificado Internacional de Vacunación contra la FA es válido 10 años a partir del $10^{\circ}$ día desde la administración. Revacunación: Cada 10 años.

\section{Enfermedad de Sindbis (SIN)}

Enfermedad originada por un Virus - RNA, género Alphavirus y familia Togaviridae: Virus Sindbis. Se mantiene en la naturaleza por transmisión entre huéspedes vertebrados (fundamentalmente aves migratorias) y vectores invertebrados (mosquitos del género Culex: C. univittatus y C.pipiens). El hombre se infecta con la enfermedad al ser picados por un mosquito infectado.

Distribución geográfica: Fue aislado por primera vez en 1952 en El Cairo. Los casos sintomáticos se han descrito en África meridional y Oriental, Egipto, Israel, Filipinas, China y Australia. Recientemente se ha vinculado a la enfermedad de Pogosta que ocurre en Finlandia.

En Kenia y Tanzania se detectan casos en todo el país siendo el riesgo es más elevado en las zonas del Lago Victoria y zonas costeras. En Somalia existe riesgo en todo el país pero es más elevado en el sur.

\section{Fiebre (de) Chikungunya}

El CHIK es un arbovirus del género Alphavirus, y familia Togaviridae que se transmite principalmente a través de mosquitos infectados de las especies Aedes aegypti y Aedes albopictus.

El reservorio son los primates no humanos. Al igual que el DEN el virus CHIK se trasmite por mosquitos del genero Aedes, siendo su principal vector el Ae aegypty seguido del Ae albopictus y Ae polynesiensis. Sin embargo durante la epidemia de la Reunión ${ }^{11}$, se detectó una mutación en el genoma del virus que favorece una mejor adaptación al Ae albopictus ${ }^{12}$. Entre los monos, la enfermedad se transmite por Ae furcifer y Ae africanus. Los mosquitos obtienen el virus ingiriendo sangre de un humano infectado. El riesgo de transmitir la enfermedad es mayor cuando el paciente está virémico durante los primeros 2-6 días de la enfermedad.
El virus del CHIK, originariamente africano y circunscrito solo a este continente y al asiático, en 2004-5 inicio una ola expansiva y explosiva a través de las islas del Océano Indico con epidemias explosivas en la isla de la Reunión e islas aledañas. Entre 2006 y 2007 reemerge en el Continente Indio con más de 1 millón de casos, y finalmente, en 2007 llego a Europa, detectándose en Italia en la región de la Romagna ${ }^{13}$ el primer brote autóctono no tropical. Desde 2008 continua su expansión por el Sur y el Suroeste Asiático.

Distribución geográfica: Principalmente en África, África Sudoriental, Australia, India, islas del océano Indico y Filipinas $^{14,15}$. Se han notificado casos en Benín, Camboya, Camerún, República Centroafricana, China, Comores, República Democrática del Congo, Timor Oriental, Guam, India, Indonesia, Malasia, Mauricio, Myanmar, Nigeria, Papúa Nueva Guinea, Filipinas, Reunión, Senegal, Sudáfrica, Sri Lanka, Tanzania, Tailandia, Uganda, Estados Unidos, Vietnam, Zimbabue.

Desde la reaparición de la enfermedad en 2004, numerosos casos se han producido en diversas partes de Asia y en la región del Índico, ejemplos de estos brotes son los que a continuación se mencionan ${ }^{14-16}$ : En el estado indio de Andhra Pradesh se han registrado casos esporádicos de DEN y un brote de CHIK, entre el 1 de diciembre de 2005 y el 17 de febrero de 2006 se notificaron 5.671 casos de fiebre con artralgias, en la zona se observó una alta densidad de Ae aegypti. Entre el 1 y el 15 de marzo se han notificado más de 2.000 casos de CHIK en la ciudad de Malegaon en el distrito de Nasik (India). Madagascar ha notificado en enero de 2006 un brote de CHIK en la ciudad portuaria de Toamasina. En 2009, el Ministerio de Salud de Malasia informó de más de 4.430 casos de CHIK, las zonas más afectadas fueron las provincias del norte de Sarawak Kedah, seguido de Kelantan, Selangor y Perak; en el segundo semestre del 2010, 549 casos, se han notificado en Sarawak. Durante el 2009, Tailandia reportó 49.069 casos de CHIK, desde mayo 2010, hay otros 1146 casos notificados, la mayoría han sido reportados en el sur del país. Más de 43.000 casos fueron también reportados en Indonesia.

En Kenia se notificó una epidemia de la enfermedad en el año 2004 con 1.300 casos (aunque se estima que superaron los 13.000 en la isla de Lamu), siendo el riesgo elevado en las provincias costeras. En Tanzania la enfermedad posee un carácter endémico afectando con más frecuencia a poblaciones rurales pero produciéndose epidemias en zonas urbanas. En Somalia desde 1989 existe evidencia serológica de afectar a diferentes zonas de Somalia como Barbera y Kismaayo, con las brotes ocurridos en el Indico desde el 2004 se aprecia un aumento del número de casos en la región.

Es interesante comentar el brote de la Isla de La Reunión ${ }^{17-19}$. En 2005, la enfermedad comenzó en las Islas Comores, después se encontró en Mauricio y Mayotte, hasta, finalmente, aparecer en La Reunión. El brote llegó a la Reunión en marzo del 2005 teniendo una escasa actividad, con sólo varios miles de casos hasta noviembre de 2005, cuando su incidencia aumentó de forma inesperada. El brote afectó a toda la Isla, con mayor actividad en el sur. Se estimo en total 236.000 casos hasta abril de 2006, alcanzado un máximo de 45.000 casos durante la semana del 29 enero-4 febrero 2006. Al final de este brote, la seroprevalencia se estimó en 38,2\% las personas que se infectaron. El Ae albopictus fue el principal vector de este brote. Desde enero de 2006, se han 


\section{JF. Plaza Torres, et al.}

declarado casos de CHIK en las Seychelles (8.818 casos sospechosos entre el 1 de enero y 28 de febrero del 2006), Mauricio, Madagascar, Comores, Malasia y en la India. La actividad de CHIK sigue su curso en la actualidad. Desde marzo a mayo del 2009, se ha informado de 67 confirmados y 23 probables casos de CHIK en Seychelles ${ }^{20}$.

Riesgo de transmisión local en Europa: El aumento de la presencia del vector, en particular del Ae albopictus, en algunas regiones de Europa implica un riesgo de transmisión local del virus a partir de casos importados. Se sabe que el vector está actualmente presente en Albania, Croacia, Bosnia y Herzegovina, Francia, Alemania, Grecia, Italia, Montenegro, los Países Bajos, Portugal (en Madeira), Eslovenia, España y Suiza. En varios países europeos se han notificado casos importados: Francia, Alemania, Italia, Noruega, República Checa, Reino Unido y Suiza. El riesgo de aparición de brotes en el continente europeo pasó a ser una realidad en el verano del 2007, cuando se informó de la existencia de 247 casos en la región italiana de Emilia-Romaña ${ }^{21}$.

En España, el centro nacional de Microbiología, durante 2006-7 diagnóstico 29 casos de infecciones por virus CHIK, en un total de 308 pacientes sospechosos ${ }^{22}$. Además del brote de Italia en Europa se ha notificado otro brote autóctono en el año 2010 en el sur de Francia y también se identificó circulación autóctona ${ }^{1,23}$.

Dada la magnitud del CHIK, con un alto nivel de viremia en el ser humano, y la importante distribución mundial de $A e$. aegypti y Ae. albopictus, podemos apreciar un riesgo potencial tanto para el viajero como para la importación del virus en nuevas áreas por viajeros infectados.

\section{Dengue (DEN)}

El DEN es considerado la más importante enfermedad vírica trasmitida por mosquitos en el mundo, calculándose que más de 2500 millones de personas viven en zonas endémicas (24). Cada año se estima que entre 50 y 70 millones de personas padecen la enfermedad, y entre 250000 y 400000 padecen $\mathrm{DHF}^{25}$.

Esta causada por un Virus - RNA, Flavivirus: Virus Dengue con los serotipos 1, 2, 3, 4 .

El reservorio son los humanos, mosquito (no claro) y monos (Malasia y África). El vector es el mosquito Stegomyia (Aedes) aegypti, S. albopictus, S. polynesiensis, S. scutellaris y el vehículo es la sangre (raro). Es una especie hematófaga diurna con mayor actividad de picadura dos horas después del amanecer y varias horas antes de la puesta de sol.

El ciclo de transmisión del virus ${ }^{26,27}$ por el mosquito comienza con una persona infectada con el DEN. Un mosquito hembra que pique a la persona e ingiera sangre en esta fase puede adquirir fácilmente el virus. Una vez que el mosquito se alimenta con sangre contaminada con virus, éste se replica en la zona embrionaria del tubo digestivo del vector, en los ovarios, el tejido nervioso y el cuerpo graso. Se difunde luego en la cavidad corporal y posteriormente infecta las glándulas salivares. Tras 7-14 días, el mosquito resulta infectante, y permanece siéndolo el resto de su vida ${ }^{28}$. Tras este periodo, el virus se encuentra en la saliva del insecto, permitiendo su inoculación a otra persona cuando se alimenta nuevamente de sangre ${ }^{29,30}$. Tras picar a una persona susceptible, el mosquito transmite el virus inoculándolo con la saliva.
La temperatura, precipitaciones y humedad son críticos para la supervivencia, la reproducción y el desarrollo del mosquito y pueden influir en la presencia del insecto y su abundancia ${ }^{31}$.

Distribución geográfica ${ }^{32-42}$ : Endémica en 115 países. Asia: China Meridional, Hainán, Vietnam, Laos, Camboya, Tailandia, Myanmar, India, Sri Lanka, Indonesia, Filipinas, Malasia, Singapur, Maldivas, Paquistán, Nueva Guinea, Bangladesh, Nepal, Taiwán, gran parte de la Polinesia y norte de Australia. Los cuatro serotipos son endémicos actualmente en África, en los últimos años se han producido brotes de DEN en la costa oriental de África, desde Mozambique hasta Somalia, Etiopía y en las islas Comores y Seychelles. En América aparece el virus en el año 1977 en zonas del Caribe y América central. En la actualidad, son endémicos en casi todo el Caribe y América latina, incluido Bolivia, Brasil, Colombia, Ecuador, Guayana Francesa, Guyana, México Paraguay, Perú, Surinam, Venezuela y América Central.

Con respecto a la variedad clínica de Dengue hemorrágico se han descrito epidemias recientes en Asia: Camboya, China, Filipinas, India, Indonesia, Malasia, Maldivas, Myanmar, Paquistán, Laos, Singapur, Sri Lanka, Tahití, Tailandia y Vietnam. En América: Brasil, Colombia, Cuba, Ecuador, El Salvador, Guatemala, Guayana, Honduras, Nicaragua, Puerto Rico, Surinam y Venezuela. En 1998 se produjo una pandemia en la que 56 países notificaron 1,2 millones de casos. Las últimas epidemias se han producido en el año 2006 en Guadalupe, Maldivas y Martinica. En la región de las Américas más de 990.000 casos han sido reportados a la OPS durante el año 2011, incluidos 12.840 casos de DHF y/o SSD. En esta región están reportando altas tasas de incidencia Brasil, Paraguay, Bolivia y Bahamas ${ }^{43-45}$.

La enfermedad es endémica en Djibouti, en los años 2002 y 2005 se notificaron casos confirmados entre militares franceses desplegados en el país. También es una enfermedad endémica en Kenia con diversas epidemias descritas desde 1982: en 1982 una epidemia del serotipo 2 asolo las zonas de Malindi y Kilifi, en 1987 se describió otra epidemia en la zona de Malindi; desde el 2005 los casos han aumentado considerablemente, especialmente en las zonas costeras del país. Con respecto a Tanzania también es una enfermedad endémica, notificándose desde la década de los 90 numerosos casos en turistas europeos. En Somalia, existe riesgo en todo el país y todo el año pero es más elevado en el sur; durante 1993 se produjeron casos en militares americanos desplegado en zona (serotipos 2 y 3 ); se ha descrito brotes epidémicos durante los años 1985, 1986 y 1989 en diversos campos de refugiados del norte del país. En Seychelles se notificaron 575 casos en el año 2006, en la actualidad solo se notifican casos esporádicos.

\section{RIESGO DE ADQUIRIR UNA ARBOVIROSIS EN ZO}

En cuanto al riesgo de adquirir una arbovirosis en el AO apreciamos como Djibouti, Somalia, Kenia y Tanzania son considerados países con elevado riesgo para adquirir enfermedades transmisibles, y si hablamos de arbovirosis todos salvo Omán son de riego elevado-medio para su adquisición.

Con un criterio clínico se han clasificado las enfermedades en cuatro grupos (leve, moderado, grave y muy grave) (tabla 1) y con un criterio operativo en tres grados (enfermedades de riesgo bajo, de riesgo medio y de riesgo elevado) (tabla 2). 
Tabla 1. Gravedad clínica de las enfermedades.

\begin{tabular}{|c|c|c|c|}
\hline Leve & Moderada & Grave & Muy Grave \\
\hline \multicolumn{4}{|l|}{ No necesaria hospitalización. } \\
\hline $\begin{array}{l}\text { La limitación de las actividades del } \\
\text { enfermo se prolonga menos de } 72 \\
\text { horas. }\end{array}$ & $\begin{array}{l}\text { Necesidad de ingreso durante } \\
1-7 \text { días y retorno posterior a la } \\
\text { actividad. }\end{array}$ & $\begin{array}{l}\text { Necesidad de hospitalización } \\
\text { o convalecencia superior a una } \\
\text { semana. Es frecuente que estos } \\
\text { enfermos sean evacuados. }\end{array}$ & $\begin{array}{l}\text { Requiere ingreso en un Hospital } \\
\text { de tercer nivel o en una UCI. La } \\
\text { enfermedad puede dejar secuelas o } \\
\text { ser mortal. }\end{array}$ \\
\hline
\end{tabular}

Tabla 2. Riesgo operativo de las enfermedades.

\begin{tabular}{|ll|}
\hline Riesgo Elevado & $\begin{array}{l}\text { Por poder afectar a gran número de personas o por su gravedad, pueden disminuir la capacidad de la Unidad, imposibilitando } \\
\text { el cumplimiento de la Misión. }\end{array}$ \\
Riesgo Medio & $\begin{array}{l}\text { Afectan a menor número de personas o causan síntomas más leves, con lo que disminuye el riesgo de que impidan cumplir la } \\
\text { Misión. } \\
\text { Se incluyen en este grupo enfermedades que sólo en ciertas condiciones podrían afectar a un porcentaje importante del } \\
\text { contingente dificultando el cumplimiento de la misión } \\
\text { Riesgo Bajo }\end{array} \quad$ Es previsible que tengan un impacto bajo en la capacidad operativa de las Unidades. \\
\hline
\end{tabular}

Tabla 3. Análisis del riesgo operativo y arbovirosis en la zona de operaciones.

\begin{tabular}{|c|c|c|c|c|c|c|}
\hline Arbovirosis en ZO & Djibouti & Somalia & Kenya & Tanzania & Omán & Seychelles \\
\hline Fiebre del del valle del Rift & & & & & & NO \\
\hline Fiebre de Crimea-Congo & & & & & & NO \\
\hline Fiebre Amarilla & NO & & & & NO & NO \\
\hline Enfermedad Sindbis & & & & & NO & NO \\
\hline \multicolumn{7}{|l|}{ Dengue } \\
\hline Fiebre de Nilo Occidental & & & & & & NO \\
\hline \multicolumn{7}{|l|}{ Chikungunya } \\
\hline Onyong-Nyong & NO & & & & NO & NO \\
\hline & ado & & Medio & & Bajo & \\
\hline
\end{tabular}

Tabla 4. Gravedad clínica de las arbovirosis.

\begin{tabular}{|c|c|}
\hline Arbovirosis en ZO & Gravedad clínica \\
\hline Fiebre del del valle del Rift & \\
\hline Fiebre de Crimea-Congo & \\
\hline Fiebre Amarilla & \\
\hline Enfermedad Sindbis & \\
\hline Dengue & \\
\hline Fiebre de Nilo Occidental & \\
\hline Chikungunya & \\
\hline Onyong-Nyong & \\
\hline
\end{tabular}

En las tablas 3 y 4 se muestran las principales arbovirosis, su gravedad y su riesgo operativo en el AO, utilizando códigos de colores.

Encontramos que hay enfermedades con riesgo de transmisión alto como la VFVR (Somalia y Kenia), DEN (Somalia, Kenia) o CHIK (Seychelles) y otras cuyo riesgo se considera intermedio, como la FHCC (aunque no tienen la capacidad de afectar a muchos miembros del contingente tienen un curso clínico muy grave), la FA, el SIN (riesgo operativo bajo) y la VWN.

\section{MEDIDAS PREVENTIVAS}

Para completar este informe se comprobaron "in situ" las medidas preventivas del contingente naval español y además se recabó información a través de los oficiales medicos de otros paises las disposiciones especificas tomadas por su unidades desplegadas en ZO. Estas medidas pretenden los siguientes objetivos:

\section{Información general de las principales enfermedades al contingente}

En general, un alto porcentaje de europeos desconoce los riesgos para la salud asociados a los viajes y no adoptan medidas preventivas ${ }^{46-50}$. En un estudio, llevado a cabo en los dos aeropuertos españoles con mayor volumen de viajeros, con objeto de analizar los conocimientos, actitudes y prácticas sobre vacunación y profilaxis antimalárica, se aportaron estos datos: el $26^{\prime} 9 \%$ de los viajeros a áreas de alto riesgo no habían recibido en ningún momento consejo sanitario, la tercera parte de los viajeros no supieron nombrar ninguna enfermedad específicamente relacionada con el lugar de destino, y lo que resulta más importante, más de la mitad de los viajeros no recibieron vacunación 
alguna y más de la tercera parte de los que viajaron al África subsahariana no recibieron profilaxis antimalárica ${ }^{51}$. En otro análisis de los viajeros que acudieron a su regreso a un centro de Medicina del Viajero ${ }^{52}$ se observó que sólo el 364\% realizaron una consulta específica antes de realizar el viaje para recibir las vacunas correspondientes, solicitar profilaxis antipalúdica o recibir consejos generales ante el viaje.

La Educación Sanitaria es la base de toda acción de Salud. Para alcanzar el éxito con un programa educativo es necesario alcanzar cuatro objetivos ${ }^{53}$ : conseguir que los individuos estén bien informada sobre los problemas de salud y enfermedad; hacer que adopte la salud como un valor fundamental; modificar los hábitos o conductas insanas, y promover las adecuadas conductas positivas de salud. Para conseguirlos, debemos elaborar mensajes informativos y persuasivos y hacerlos llegar a la población. En nuestro caso hemos utilizado como métodos de información, métodos directos: el diálogo y la charla y métodos indirectos: carteles y prensa (figura 3).

Resulta útil la información general al contingente acerca las características básicas de la de las principales enfermedades desde el punto de vista de Salud Publica, y sus vectores. Es necesario también educar al contingente en acciones simples de control del vector, fomentando su participación activa tanto en las medidas encaminadas a la destrucción de los criaderos como en las medidas de protección contra la picadura del mosquito.

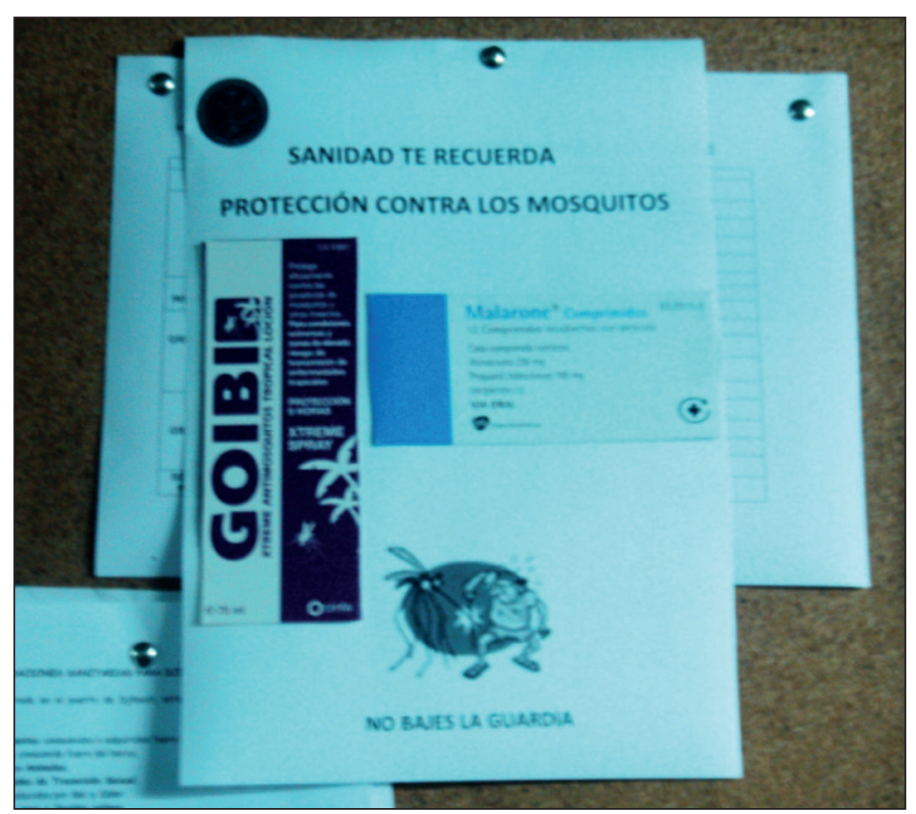

Figura 3. Folleto informativo sobre arbovirosis repartido al contingente español.

Esta Educación debe comenzar antes del despliegue, y debe ser canalizada a través de los servicios sanitarios. Una vez en zona, son importantes los recordatorios, es decir, alguna indicación o señal que recuerde la existencia de un problema de salud y/o las acciones necesarias para combatirlo. Son medidas útiles: los anuncios públicos distribuidos en lugares concurridos, recordando la existencia de mosquitos y cómo protegerse de sus picaduras, las charlas informativas periódicas sobre las principales enfermedades infecciosas en el AO y la difusión de las medidas de prevención mediante pequeñas cuñas en la Orden diaria del Buque.

Otro pilar de estos programas, al ser estas enfermedades relativamente desconocidas en nuestro medio, es insistir en su conocimiento y manejo en Territorio Nacional (TN) por parte del personal sanitario de cada rotación.

El objetivo de esta información es que la dotación esté informada de los siguientes aspectos: Riesgo de infección. Conocer que la trasmisión se produce por mosquitos infectados y la importancia de los métodos barrera. Saber que los primeros síntomas de la enfermedad pueden ser benignos e inespecíficos y que se debe sospechar la enfermedad si a partir de una semana después de llegar a una zona endémica aparece fiebre inexplicable, acompañada o no de otros síntomas. Que en caso de producirse un acceso de fiebre se debe consultar a un facultativo.

\section{Control ambiental}

Esta medida debe abordarse de forma continua y pretende la eliminación de posibles criaderos. Durante las estancias en puerto todos aquellos objetos que acumulan agua de lluvia o son usados para almacenar agua deben ser cubiertos o desechados adecuadamente. La presencia de agua es de gran importancia para su crecimiento, ya que los huevos del mosquito requieren agua estancada para transformarse en adultos.

Debe optimizarse el sistema de recogida, transporte y destino final de los residuos sólidos, especialmente aquellos que puedan acumular agua. Es igualmente importante mantener la basura tapada y seca. En destacamentos en tierra debe abordarse una estrategia de saneamiento ambiental, con medidas destinadas a mejorar el sistema de abastecimiento de agua y mantener los aljibes completamente cerrados y sin grietas.

Para la evaluación de la infección por los vectores en una región determinada y, consecuentemente, de las campañas de control, se utilizan índices entomológicos. Como ejemplo de ellos, los indicadores entomológicos básicos más empleados en el control vectorial del DEN en América son ${ }^{24}$ : el Índice de infestación predial (domiciliario) o índice larvario: porcentaje de casas con recipientes conteniendo larvas o pupas de Ae. aegypti, en relación al total de casas examinadas y el Índice de Breteau: número de recipientes positivos para larvas o pupas de Ae. aegypti, por cada 100 residencias.

\section{Protección frente a los mosquitos}

La exposición a las picaduras de artrópodos puede reducirse si los viajeros modifican sus patrones de actividad o comportamiento. Aunque los mosquitos pueden picar a cualquier hora del día, algunas especies tienen mayor actividad para picar durante el día (como el Aedes spp.) y otros son más activos de orto a ocaso (como el Anopheles spp.). Evitar las actividades al aire libre como acción preventiva a las horas de máxima posibilidad de picadura puede reducir el riesgo así como evitar zonas de alta infestación. 


\section{Arbovirosis y operación ATALANTA: riesgo para viajeros y medidas de prevención y control}

Entre las recomendaciones con el fin de evitar las picaduras destacamos las siguientes:

- Durante los periodos en que pican los mosquitos se debe permanecer en interiores $y$, si es posible, con aire acondicionado y/o tela mosquitera en puertas y ventanas.

- Evitar perfumes o colonias fuertes.

- Utilizar uniformes con pantalón largo y mantener las mangas bajadas.

- Utilizar mosquiteras en la cama correctamente colocadas. El tamaño de la malla no debe ser mayor de 1'5 mm. Las telas mosquiteras pueden adquirirse impregnadas con insecticida (un piretroide), lo que favorece el efecto repelente hacia el artrópodo, es necesario recordar que el efecto suele desaparecer a los 6-8 meses.

- La higiene personal ayuda a evitar la producción o a eliminar de la piel sustancias atrayentes para los mosquitos.

Los repelentes son sustancias que se aplican sobre la piel para ahuyentar a los insectos y así evitar sus picaduras. Los repelentes no matan al insecto pero lo alejan, y son una de las mejores armas en la prevención de enfermedades transmitidas por vectores. Cuando el mosquito se acerca al hospedador los repelentes actúan, en líneas generales, obstruyendo el sensor del artrópodo y lo confunden para que no pueda aterrizar y picar.

Las primeras investigaciones se hicieron por necesidades militares. El primer repelente que se empleó fue el aceite de citronella, que se sustituyó por una sustancia de síntesis denominada dimetil ftalato y finalmente, éste, que se deseaba sustituir por los problemas que originaba su efecto disolvente orgánico, se desarrolló el DEET (dietil toluamida), que fue patentado por el US Army en 1946. DEET se popularizó hasta el punto de que la mayoría de los repelentes hasta hoy se han formulado con él. Sin embargo, no es un repelente perfecto, debido a su toxicidad y propiedades irritantes, lo que justifica que se haya intentado desarrollar sustancias alternativas.

La protección y duración del repelente pueden variar en función de la temperatura ambiente, la sudoración y la exposición al agua. Como normas generales de utilización pueden citarse las siguientes:

- Impregnar las partes de piel expuestas, sin olvidar cuello, muñecas y tobillos, respetando mucosas y piel dañada.

- No esparcir en áreas cerradas sin ventilación.

- No rociar directamente en la cara sino en las manos, para después aplicarlo en la cara evitando el área de los ojos y la boca.

- Retirar con agua y jabón cuando ya no sea necesario el repelente.

- Cuando se utilice junto con protectores solares, el repelente debe utilizarse sobre el protector solar.

Algunos de los repelentes más utilizados son los siguientes:

Dietil toluamida, DEET: Es normalmente el repelente de primera elección. El DEET tiene suficiente eficacia como repelente de insectos. Produce unas desagradables sensaciones en los terminales sensitivos de los insectos, y por ello, su efecto repelente es muy marcado cuando el insecto se posa en alguna superficie tratada. También presenta una elevada volatilidad, por lo que genera un cierto entorno repelente en las zonas donde se aplica. Se puede presentar en diversas formulaciones y presentaciones, (figura 4).

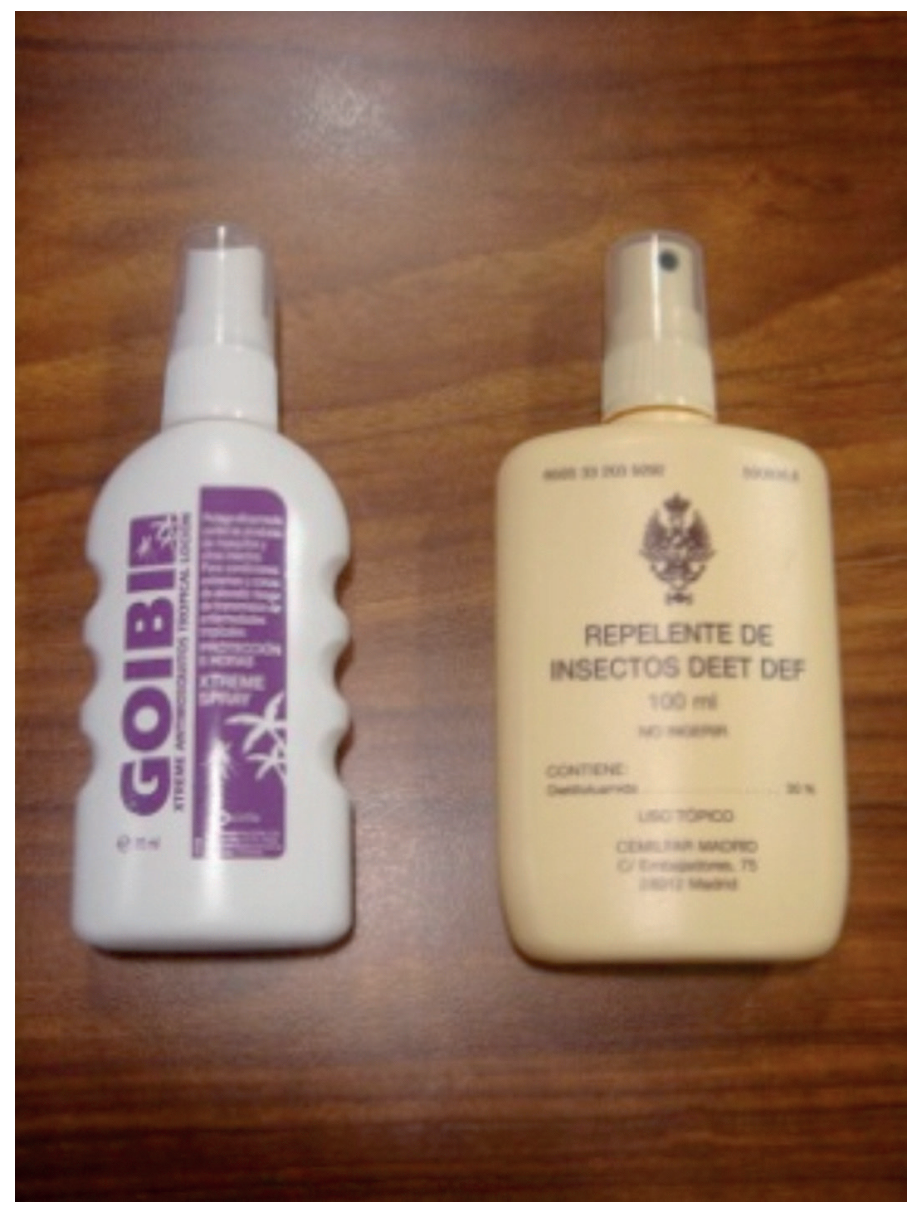

Figura 4. Repelente de insectos empleado por los miembros del contingente español desplegado a zona de operaciones.

Su eficacia depende de la concentración. En general, no son necesarias altas concentraciones, siendo suficiente del 10 al 35\% para proporcionar una adecuada protección. Presenta un alto grado de absorción cutánea unido a un cierto grado de toxicidad, especialmente en niños. De hecho, la Academia Americana de Pediatría recomienda que los repelentes usados en niños no contengan más de un $10 \%$ de DEET y lo desaconseja a menores de 36 meses $^{54}$. Tiene un cierto efecto irritante en pieles con heridas. Concentraciones superiores al 50\% rara vez son indicadas y se hace en lugares donde se produce una rápida pérdida del efecto en la piel como es el caso de ambientes con altas temperatura y elevados niveles de humedad. La duración depende de la concentración, así por ejemplo las concentraciones del $20 \%$ ofrece una protección de unas 12 horas, esta duración depende de la temperatura y la humedad de la zona, disminuyendo un $50 \%$ la efectividad por cada $10^{\circ} \mathrm{C}$ de elevación.

Está en cuestión la existencia de una sinergia peligrosa cuando se emplea junto con piretrinas, así como la posible interac- 


\section{JF. Plaza Torres, et al.}

ción con piridostigmina ${ }^{55}$. Por tanto, habrá que tener especial cuidado cuando el interesado viaje a zonas donde se emplee la permetrina como método de prevención de picaduras, o cuando se utilice pretratamiento anticolinesterásico en previsión de presencia de agentes neurotóxicos (en ambiente NBQ).

Citronella y Eucaliptus Maculata Spp Citriodara: El primero es un extracto de los derivados terpénicos presentes en diversas especies vegetales y está compuesto de citronela, limoneno y otras sustancias similares. Sobre él segundo se han desarrollado ensayos hasta dar con el extracto más activo, que es el PMD (Pmentano-3,8-diol). Se piensa que ambos actúan provocando un efecto desagradable sobre las terminaciones sensitivas así como un bloqueo de la percepción química que usan para orientarse. A pesar de que la citronella y el eucalipto son derivados naturales con pocos efectos secundarios, su poca duración y la escasa intensidad de su efecto hace que solo se recomienden cuando no se disponga de otro repelente.

Bayrepel o Acido 1-Piperidincarboxílico, 2-(2-Hidroxietil)1-Etilpropilester (Picaridina o Icaridina) ${ }^{56}$ : Su mecanismo de acción se basa en interferir los receptores específicos de los insectos. Se ha demostrado que es eficaz en moscas y mosquitos y que a concentraciones iguales tiene un tiempo de protección siempre igual o mayor (hasta un $40 \%$ ) a otros principios activos dependiendo del tipo de especie. En concentraciones del $20 \%$ su actividad puede llegar hasta las 8 horas. No es agresivo con otros materiales, ni con la piel ni produce irritaciones. Tiene buenas propiedades cosméticas y se puede recomendar incluso para las pieles sensibles.

Piretrinas: Además de su propio efecto insecticida, las piretrinas poseen una potente acción repelente de insectos, pero su coste y el interés de reservarlo para otros usos aconsejan reservar su uso en prevención al tratamiento superficial de mosquiteras.

En muchas circunstancias pueden impregnarse con insecticida los tejidos, por ejemplo, con piretroides como la permetrina o la alfacipermetrina. Se utilizan impregnando la ropa y telas mosquiteras, nunca directamente sobre la piel. Es posible adquirir permetrina diluida al 2-5\% que puede pulverizarse sobre la ropa y dejar secar. El efecto repelente suele durar unas dos semanas y resistir varios lavados, pudiendo repetirse posteriormente el proceso, ya que no altera los tejidos ni deja mal olor.

Tabla 5. Acrónimos.

\begin{tabular}{|ll|}
\hline Fiebre de Chikungunya & CHIK \\
\hline Fiebre del Nilo Occidental & VWN \\
Centro para el control de Enfermedades & CDC \\
Unión Europea & UE \\
Área de Operaciones & AO \\
Dengue & DEN \\
Zona de Operaciones & ZO \\
Fiebre del Valle del Rift & VFVR \\
Fiebre Hemorrágica de Congo-Crimea & FHCC \\
Fiebre Amarilla & FA \\
Enfermedad de Sindbis & SIN \\
Dengue Hemorrágico & DHF \\
Síndrome de Shock por Dengue & SSD \\
Territorio Nacional & TN \\
\hline
\end{tabular}

También es posible rociar con insecticidas a base de piretrinas las habitaciones, o bien utilizar difusores de estas sustancias. En caso de ausencia de electricidad se pueden usar espirales fumígenos.

Aunque no es objeto de este texto la descripción exhaustiva de los medios de control de plagas a disposición de los contingentes desplegados. Existe experiencia en otras misiones de la eficacia del empleo de alfacipermetrina como adulticida. Los piretroides sintéticos, familia a la que pertenece esta sustancia, tienen una acción repelente, pero sobre todo, tienen una acción tóxica una vez que atraviesan el exoesqueleto quitinoso. El tratamiento adulticida debe ser complementado con los tratamientos larvicidas.

\section{CONCLUSIONES}

- Creemos de interés para la Sanidad Militar que sus miembros conozcan los riesgos a los que se enfrentan las fuerzas desplegadas en ZO para poder adoptar las medidas adecuadas de información, prevención y control de las mismas. La adopción de medidas de prevención, de forma general y en nuestro caso concreto de las arbovirosis, deben iniciarse, en TN, y preferiblemente integrada en la Fase de Planeamiento de la Operación, solo así puede garantizarse una auténtica coherencia y continuidad del esfuerzo preventivo.

- La alta incidencia de DEN, junto con las epidemias recientes de CHIK y el riesgo de transmisión alto de VFVR, hacen que exista un riesgo potencial para los contingentes desplegados en Zona y aconsejan un conocimiento profundo de la epidemiología, manifestaciones clínicas y opciones de prevención y control de estas enfermedades.

- Consideramos la Educación Sanitaria, por personal adecuadamente formado, un arma fundamental para prevenir las principales enfermedades de la $\mathrm{ZO}$, tenemos que concienciar a las dotaciones de la importancia de las mismas debiendo ser capaces en el caso de las arbovirosis de dar información, clara y concisa, y que incluya, una descripción general de las mismas, de cómo se trasmite, de cómo se manifiesta, de lo importante que es un diagnostico y tratamiento a tiempo, así como de informar de cómo protegerse de las picaduras de los mosquitos. Los programas de Educación Sanitaria deben ser reiterados y continuados en el tiempo, fáciles de entender, con mensajes claros y concisos y con un lenguaje adaptado al público al que va dirigido, pudiendo establecer medidas de recuerdo, como carteles, colocados en sitios concurridos de las bases.

- Como otras enfermedades de los trópicos, las arbovirosis han experimentado un aumento progresivo de casos autóctonos e importados, mientras la expansión de sus vectores lleva de nuevo la amenaza a latitudes donde no existían. Todo ello refuerza sin duda lo expresado en los puntos anteriores.

- El control de estas enfermedades se beneficia de un enfoque multidisciplinar basado en dos pilares fundamentales, que podemos identificar como la Medicina Tropical y la Entomología Sanitaria. 


\section{Arbovirosis y operación ATALANTA: riesgo para viajeros y medidas de prevención y control}

\section{BIBLIOGRAFIA}

1. Aranda C, Eritja R, Roiz D: First record and establishment of the mosquito Aedes albopictus in Spain. Med Vet Entomol 2006; 20:150-2.

2. Grandadadam M, Caro V, Plumet V. Chikungunya virus, southeastern France. Emerg Infect dis 2011; 17: 910-13

3. Lanciotti RS, Roehrig JT, Deubel V. Origin of the West Nile virus responsible for an outbreak of encephalitis in the northeastern United States. Science 1999; 17(286):2333-7

4. Lundstrom, J.O. Mosquito-borne viruses in western Europe: a review. J Vector Ecol 1999; 24 (1):1-39.

5. United Nation World Tourism Organization. UNWTO World Tourism Barometer. 2009;7. Disponible en: http://www.unwto.org/facts/eng/barometer.htm.

6. Freedman DO, Weld LH, Kozarsky PE. Spectrum of disease and relation to place of exposure among ill returned travelers. N Engl J Med 2006; 354:119-30.

7. Jelinek T, Myrvang B. Surveillance of imported infectious diseases in Europe: report from the 4th TropNetEurop workshop. Acta Trop 2004; 91(1):47-51.

8. Jelinek T, Schulte C, Behrens R. Imported falciparum malaria in Europe: sentinel surveillance data from the European network on surveillance of imported infectious diseases. Clin Infect Dis 2002; 34:572-76.

9. US Department of Defense Directive, Force Health Protection (FHP): 620004. Washington, Dc: US Department of Defense 2004.

10. Llanos JK. The reporting and recording of unspecificied malaria in the military 1998-2007. Us Army Medical Department 2009; 42-5.

11. D'Ortenzio E, Grandaham M, Balleydier E. Trains of Chikungunya virus, Reunion Island, 2010. Emerg Infect dis 2011; 17: 309-11.

12. Tsetsarkin K, Vanlandingham D, McGee C. A single mutation in Chikungunya virus affects vector specificity and epidemic potential. Plos Pathog 2007; 3: 201-2.

13. Seyler T, Rizzo C, Finarelli Ac. Autochthones Chikungunya virus transmission may have occurred in Bologna, Italy, during the summer 2007 outbreak. Euro Surveill 2008; 17: 13-16.

14. Chikunguya en Guía de Enfermedades Infecciosas importadas. Ministerio de Sanidad y Consumo, Madrid 2009.

15. Lanciotti RS, Kosoy O, Laven JJ. Chikungunya virus en viajeros de EE.UU. que regresan de la India, de 2006. Emerg Infect Dis 2007; 13 (5) :764-7.

16. Parola $P$, de Lamballerie X, J Jourdan. Virus de Chikungunya en viajeros que regresan de islas del Océano Índico. Emerg Infect Dis 2006; 12 (10):1493-9.

17. Brote de Fiebre de Chikungunya en la Isla Reunión. Boletín Epidemiológico. Centro Nacional de Epidemiología. Instituto de Salud Carlos III, Madrid 2005; 13: 253-54.

18. Chikungunya outbreak in Reunion, a French overseas department. Disponible en htttp://www.eurosurveillance.org/ew/2006

19. Gerardin V, Perrau J, Fierau A. Estimación de la prevalencia en el brote de la Isla de la Reunión: encuestas epidemiológicas. BMC Infect Dis 2008: 97-9.

20. Centers for Disease Control and Prevention. Travelers health. Disponible en http://wwwnc.cdc.gov/travel/outbreaks.

21. Rezza G, Nicoletti L. La infección del virus de Chikungunya en Italia: un brote en una región templada. Lancet 2007; 370:1840-6.

22. Sánchez-Seco MP, Negredo A, Puente S. Microbiological diagnosis of Chikungunya virus in Spain (2006-2007): case detection in travelers. Enferm Infecc Microbiol 2009; 27: 457-61.

23. Grandadadam M, Caro V, Plumet V. Chikungunya virus, southeastern France. Emerg Infect dis 2011; 17: 910-13.

24. Schtazmayer H, Nogueira R: Dengue. Curso de Enfermedades Tropicales. Universidad de Salta, Argentina, 2004.

25. Calisher CH: Persistent emergence of dengue. Emerg Infect Dis 2005; 11:738-9.

26. Gaunt MW, Sall AA, de Lamballerie X, Falconar AK, Dzhivanian TI, Gould EA. Phylogenetic relationships of flaviviruses correlate with their epidemiology, disease association and biogeography. J Gen Virol 2001; 82:1867-76.

27. Wang E, Ni H, Xu R, Barrett AD, Watowich SJ, Gubler DJ, Weaver SC: Evolutionary relationships of endemic/epidemic and sylvatic dengue viruses. J Virol 2000; 74:3227-34

28. Moncayo AC, Fernández Z, Ortíz D, Diallo M, Sall A, Hartman S, et al. Dengue emergence and adaptation to peridomestic mosquitoes. Emerg Infect Dis 2004; 10:1790-96.

29. Salazar MI, Richardson JH, Sánchez-Vargas I, Olson KE, Beaty BJ. Dengue virus type 2: replication and tropisms in orally infected Aedes aegypti mosquitoes. BMC Microbiol 2007; 7:9-14.
30. Joshi V, Mourya DT, Sharma RC. Persistence of dengue-3 virus through transovarial transmission passage in successive generations of Aedes aegypti mosquitoes. Am J Trop Med Hyg 2002; 67:158-61.

31. Brunkard JM, Robles JL, Ramírez J, Cifuentes E, Rothenberg SJ, Hunsperger EA, Moore CG, et al. Dengue Fever seroprevalence and risk factors, Texas-Mexico border, 2004. Emerg Infect Dis 2007; 13:1477-83.

32. Effler PV, Pang L, Kitsutani P, Vorndam V, Nakata M, Ayers T, et al: Dengue fever, Hawaii, 2001-2002. Emerg Infect Dis 2005; 11:742-749.

33. Pandey BD, Morita K, Khanal SR, Takasaki T, Miyazaki I, Ogawa T, et al: Dengue virus, Nepal. Emerg Infect Dis 2008; 14:514-5.

34. Wichmann O, Lauschke A, Frank C, Shu P, Niedrig M, Huang J, et al: Dengue antibody prevalence in German travelers. Emerg Infect Dis 2005; 11:762-5.

35. Lindbäck H, Lindbäck J, Tegnell A, Janzon R, Vene S, Ekdahl K: Dengue fever in travelers to the tropics, 1998 and 1999. Emerg Infect Dis 2003; 9:438-42.

36. Kanesa-thasan N, Iacono-Connors L, Magill A, Smoak B, Vaughn D, Dubois D, et al. Dengue serotypes 2 and 3 in US forces in Somalia. Lancet 1994; 343:678

37. Pinheiro FP, Corber SJ. Global situation of dengue and dengue haemorrhagic fever and its emergence in the Americas. World Health Stat Q 1997; $50: 161-9$.

38. Rodríguez-Roche R, Álvarez M, Holmes EC, Bernardo L, Kouri G, Gould EA, et al. Dengue virus type 3, Cuba, 2000-2002. Emerg Infect Dis 2005; 11:773-4.

39. Peyrefitte CN, Pastorino BAM, Bessaud M, Gravier P, Tock F, CouissinierParis P, et al. Dengue type 3 virus, Saint Martin 2003-2004. Emerg Infect Dis 2005; 11:757-61.

40. Barcelos L, Batista A, Portela G, Paiva B, Germano J, Bonjardim CA, Peregrino PC, et al. Dengue virus 3 genotype 1 associated with dengue fever and dengue hemorrhagic fever, Brazil. Emerg Infect Dis 2008; 14:314-16.

41. Siqueira JBJ, Martelli CMT, Coelho GE, Simplicio ACDR, Hatch DL. Dengue and dengue hemorrhagic fever, Brazil, 1981-2002. Emerg Infect Dis 2005; 11:48-53.

42. Nogueira RMR, Schatzmayr HG, de Filippis AMB, dos Santos FB, da Cunha RV, Coelho JO, et al. Dengue virus type 3, Brazil 2002. Emerg Infect Dis 2005; 11:1376-81.

43. Domingo C. Dengue importando en Europa: caracterización microbiológica. Enf Emerg 2006; 8:97-8.

44. Domingo C. Diagnóstico de infecciones secundarias por dengue en viajeros. Enf Emerg 2004; 6:143-4.

45. Yellow Book 2012. Disponible en http://wwwnc.cdc.gov/travel.

46. Van Herck K, Van Damme P, Castelli F. Knowledge, attitudes and practices in travel-related infectious diseases: the European airport survey. J Travel Med 2004; 11(1):3-8.

47. Angell SY, Behrens RH. Risk assessment and disease prevention in travelers visiting friends and relatives. Infect Dis Clin North Am 2005; 19 (1):49-65.

48. Boggild AK, Yohanna S, Keystone JS, Kain KC. Prospective analysis of parasitic infections in Canadian travelers and immigrants. J Travel Med 2006; 13 (3):138-44.

49. Fenner L, Weber R, Steffen R, Schlagenhauf P. Imported infectious disease and purpose of travel, Switzerland. Emerg Infect Dis 2007; 13 (2):217-22

50. Spira A. Assessment of travellers who return home ill. Lancet 2003; 361:1459-69.

51. Lopez-Velez R, Bayas JM. Spanish travelers to high-risk areas in the tropics: airport survey of travel health knowledge, attitudes, and practices in vaccination and malaria prevention. J Travel Med 2007; 14 (5):297-305.

52. López Vélez R, Navarro Beltrá M, Jiménez Navarro C. Estudio de Inmigración y Salud Pública en enfermedades Infecciosas Importadas. Ministerio de Sanidad y Consumo, Madrid 2007

53. Salleras L. Métodos y medios de educación sanitaria. En: Piédrola G, del Rey J, Domínguez M, Cortina P, Gálvez R, Sierra A, et al. Medicina Preventiva y Salud Pública, 9a ed. Barcelona: Salvat editores; 1991:861-70.

54. Koren G, Matsui D, Bailey B. DEET based insect repellents: safety implications for children and pregnant and lactating women. Can Med Assoc J 2003; 169:20912

55. Pita R, Anadón A, Martínez-Larrañaga M: Estado actual del pretratamiento de las intoxicaciones por agentes neurotóxicos de guerra con piridostigmina y otras alternativas farmacológicas. Rev. Toxicol 2003; 20:1-7.

56. Medical Letter. Picaridin A new insect repellent. Med Lett Drugs Ther 2005; 47:467. 